which each explorer gives, every year, the summary of the work done to the director of the survey, has not yet been issued, although the volume in which it ought to be inserted was printed three years ago. The stopping of the distribution of the "Eleventh Annual Report" is somewhat mysterious. Two other printed Annual Reports, the twelfth and thirteenth, remain also undistributed, waiting for the distribution of the eleventh.

Mr. A. Hyatt, in a printed letter in The American Geologist for April, 1893, p. 281, admits that his verbal opinion, quoted by me at page 213 of the same periodical, "is correct;" but that he had "at present absolutely no opinion about the age of rocks of this region." A rather curious conclusion for an explorer who has passed two months on the same ground where I was only two dass, and who has studied the collection of fossils he made during a whole winter.

Evidently there is some secret about it. My old adversaries, almost all alive now, with the exceptions of the two Shumards, Meek and Newbery, are still at woriz against me. But I have resisted their combined attacks during forty years, and I can continue very well the defence of my observations and opinions.

However, I shall say nothing more for the present, waiting until after the publication, by some paleontologist, of the fossils collected at the Tucumcari by Messrs. Hill, Hyatt, and Cummins, with descriptions and good figures; for it is absolutely useless to discuss any longer, without proper documents in the hands of geologists, in order that evergone interested in the question may be able to judge for himself as to the conclusions arrived at by the different parties.

Cambridge, Mass. JULES MARCOU.

\section{Natural and Artificial Cements in Canada.}

Your issue of March 31, 1893, contains an article on "Natural and Artificial Cements in Canada," which in part is incorrect, and I wish to set you right with regard to the class of raw material from which the "Star" Portland cement is manufactured

In the first place, Star cement is manufactured from shell marl, which is thoroughly decomposed, and containing from 95 to 98 per cent pure carbonate of lime, the clay used is an allu vial blue clay.

The analyses of our clays and marl show them to be of superior quality and equal to any deposits of a similar nature; this has also been fully demonstrated in the practical results obtained by users of the cement when manufactured.

Napanee Mills, June 12.

\section{Sound and Color.}

On reading Professor Underwood's paper on the above subject in Science for June 16th, some rather peculiar experiences of my own, which I have never read or heard of in others, were freshly brought to mind.

When intently listening to certain, but by no means all, eminent speakers, and to a few operatic singers of great renown, I have for some years past distinctly detected, or rather have involuntarily become conscious of, an emanation of color from the head of the speaker or singer with each distinct tone of the voice. The more impassioned the words and tones the more intense the color, and the larger the visible aureole or color area. The color has thus far been limited, with a few exceptions, to a transparent and ethereal but decided blue. It emanates suddenly with each explosion of sound, passes upward like a thin cloud of smoke, and fades like a swiftly dissolving view. I noticed it for the first time while listening to Professor Felix Adler, later on when listening to Colonel Ingersoll, faintly over the head of William Winter; again quite distinctly in case of General Sherman and General Horace Porter, faintly in case of some other public speakers, including Anna Dickinson, Helen Potter, the elocutionist, and some eminent divines, but not at all in case of President Cleveland and some other equally prominent public men.

In case of singers, the most noted instances I can recall are the DeRetszke brothers, Jean and Edward, Mdme. Emma Eames, Lilli Lehmann, Mdme. Albani, Vogel, and Gudehus,

In case of Mdme. Lehmann the blue color verged tow ands a liquid green, and with Albani it was a pale sheen of silver vapor. In case of Vogel, the tenor, the aureole was an evanescent and very pale straw color. In Mdme. Mielke the blue became a velvety purple or violet. Mdme. Nordica emitted an aureole of pale, translucent gold; Emma Juch gives me the impression of a delicate and liquid pink, while Patti seemed to emit no distinguishing color, but rather a kaleidoscopic blending of many colors.

I should be glad to hear from others who have noted similar phenomena, for I have been inclined to question the reliability of my own impressions, vivid as they have been, and many times repeated. Professor Underwood's recital inclines me to accord them a little more respect. Washington Helghts, City.

Samuel S. Wallian, M.D.

\section{Age of Guano Deposits.}

THE following particulars, recently given me by a friend who, years ago, was a sailor, and whom $I$ know to be a man of the strictest veracity, may be of interest as possibly throwing some light on the age of guano deposits.

In the year 1840 his vessel loaded with guano on the island of Ichabo, on the east coast of Africa. During the excavations which were necessary, the crew exhumed the body of a Portuguese sailor, who, according to the head-board, on which his name and date of burial had been carved with a knife, had been interred fifty-two years previously. The top of this head-board projected two feet above the original surface, but had been covered by exactly seven feet of subsequent deposit of guano.

U. S. National Museum, Washington, D.C., June \&3.

ROBERT RIDGWAY.

\section{Correction.}

IN 1887 I published in the Canadian Record of Science an account of a Permian glacial moraine in Prince Edward Island. I have recently examined this formation more carefully, and am not at all positive about its age. The bedding and jointage are conformable with the underlying formation, but the cementing material is purely calcareous, and the induration, though complete, may be recent. In the absence of organic evidence, I do not think we can positively say that this conglomerate is not Quaternary.

North River, P. E. Island.

F. BAIN.

\section{BOOK-REVIEWS.}

Geological Survey of Missouri. Vol. II. A Report on the Iron Ores of Missouri. By Frank L. Mason. Jefferson City, December, 1892. Plates, Map, etc. $366 \mathrm{p}$.

Vol. III. A Report on the Mineral Waters of Missouri. By Paul Schweitzer. Jefferson City, December, 1892. Plates, Map, etc. $256 \mathrm{p}$.

THERE are but few States in the Union that have not had at some time or other geological surveys of a part or the whole of their territory. As a general rule, the surveys have been conducted by different geologists, the same one seldom holding his position for a long period, and, in point of fact, the survey itself frequently ending before a decade has elapsed. There are, of course, notable exceptions to this, Minnesota, for example, where the State geologist has issued twenty annual reports, and New York, which has enjoyed an almost uninterrupted existence since 1836. Yet more remarkable in this latter case is the fact that the present head of the survey has been such for nearly fifty years and was one of the original corps in 1836. This veteran, as everyone knows, is Professor James Hall, still one of the most indefatigable of all American geologists.

The State of Missouri has had numerous surveys, which have been carried on under various heads. The first survey existed from 1853 to 1862 , and published five reports; the second lasted from 1870 to 1874 , and issued four reports; the third from 1876 to 1879 , and published only one report; while the fourth has lasted from 1889 to date, and has published three bulky volumes, of which the present ones are two, five bulletins, an atlas of maps, and a biennial report. We thus see that under the present management more work has been done than in any of the other surveys lasting twice as long. 
In Vol. II. of the reports Mr. Mason has given much valuable information relative to the iron ores. In his introductory remarks he discusses the forms in which iron occurs and the relative value of the various ores. He then takes up the kinds found in Missouri, describes their distribution, and examines in detail coarse and fine specular ore, limonite, red hematite, carbonate, and bog ores. In this discussion, various facts are brought out of interest and value to geologists and students of physical geography. For example, it is concluded that the strata lying about the Archæan outcrops of the Ozark Mountains are of Cambrian age instead of Lower Silurian, as they have been almost universally considered. An excellent description is given of Iron Mountain, Pilot Knob, and other large deposits of ore, and this is followed by an account of the probable origin of the ore beds. The veins are regarded as veins of infiltration, fissures occurring in the rocks having been filled by the solvent action of percolating water through iron-bearing porphyries. The changes produced in topography of preCambrian time by this action of water are briefly sketched as follows:-

"In the first place, whatever the origin of the porphyries, it is allowable to imagine the porphyry region to have been, in preCambrian times, mountainous, or at least hilly. These bills and valleys must have had cracks or fissures in the rocks as we find them to-day. Naturally, erosion or weathering and denuding agencies would begin at the highest points. The products of disintegration would wash from the higher to the lower points. Iron dissolved from the decomposed rocks would, by means of percolating waters, find its way to the fissures in the unweathered rocks at a lower point. In these fissures it would be precipitated, either chemically, by coming into contact with alkaline or other reagents, or would, by slow absorption of oxygen, be made insoluble. This in time would fill the crevices and fissures in the lower rocks with a substance much less susceptible to weathering influences. The rock-mass thus cemented would, as a whole, also tend to resist weathering more effectually than the rock not thus protected. Iron deposits filling fissures would not be formed at the highest points, since solution would tend to carry it either deeper into the hills or into the valleys below. The result of this would inevitably be that the erosive agencies would be much more effective on the elevated portions of the country than on the lower. Gradually the hills would tend to reach the valley ievel; the valley country, being protected by iron dykes and reins, would resist such erosion. The final result would be that in many cases the hills would be changed to valleys and the valleys to hills" (pp. 57-58).

An interesting account of the Ozark uplift occupies one of the chapters. The region generally goes by the name of the "Ozark Mountains," but it is mountainous in name only. It is an elliptical, dome-shaped elevation, about 140 miles wide and about 200 miles long. Its greatest elevation is about 1,100 feet The average slope to the southeast is a little more than one degree, while to the northeast it is less. The region may be divided into (1) plateau, (2) billy or " mountainous," and (3) river bottoms. In the plateau region the rivers have their origin. The surface is mostly gently rolling, well-drained, and not steep enough to prevent easy tillage. Following the streams down in either direction the bluffs grow higher and higher, the streams more numerous, and there is soon reached a country cut by deep cañons, or gorges, with steep-walled divides. This is the "mountainous" region, but when one climbs to the summit of the divide, instead of a commanding view, there appears to be a plain spread out on all sides. The "mountain" crests are all at the same level. Floating down the streams the bluffs and hills grow higher and higher, but the fact is soon apparent that, instead of mountains and hills having been thrust up, the plateau has been etched into relief by the streams. The river bottoms begin in the mountain region, at first of little value or extent, but gradually widening out to from one-half to two miles. Here the hills lose their sharp crests and steep slopes, and the bottoms rise gradually by an easy slope to the uplands.

Throughout the region the streams are peculiar. In many cases they spring directly from the foot of a tall cliff and begin at once to cut their gorges. These grow deeper, the walls frequently rising, by a succession of precipices of from 50 to 100 feet, to a height of 500 feet. The courses of the streams are very tortuous. At one place the Osage River flows a distance of seventeen miles when it can be intersected by crossing overland only a single mile. A departure from a direct line of from three to seven miles is not at all uncommon. The absence of bowlders is also noticeable; this being due to the fact that the masses of rock falling from the cliffs are soluble limestone or friable sandstone, and both are quickly removed. The streams are also of large size, yet water courses on the surface generally have no water in them. At the same time many rise to impassable floods in a few hours. In May, 1892, the Current River rose 27 feet in about eight hours. The floods subside as rapidly as they rise, the cause in both cases being the character of the country. There is nothing to conserve the water and it runs off as fast as it falls.

Yet another feature of the region is in the large springs. One of these, called Meramac Spring, is said to flow at the rate of 10,000 cubic feet per minute. Current River rises from a spring of about equal size, and these are but two out of a large number. These springs are, of course, only the outlets of underground rivers. Sinking Creek flows for a long distance as a surface stream. "A few miles from where it empties into Jack's Fork it runs into a cul de sac, formed by a crescent-shaped mountain 500 or 600 feet in height. Just before reaching this mountain it sinks from sight and reappears a mile away on the other side of the mountain in the form of a large spring." Naturally, with a scant coating of soil on the hills, the vegetation is not there luxuriant. Twenty or thirty years ago the hills were reported to be bare, but now they are covered with a thin growth of jack-oak, hickory, cedar, and yellow pine. But the growth in the river bottoms, where the soil is rich, is luxuriant, the trees being close together and of gigantic height. Here are found sycamore, gum, elm, water-maple, water-birch, ash, hickory, and numercus oaks. All are so connected by a net-work of vines that it is nearly impossible to get between them.

The age of various sandstones and limestones that have been described in different Missouri reports has long been a vexed question and one that has given all who have attacked it great trouble. This question is taken up by Mr. Mason, and his conclusions may be summed up as follows:-

The geological age of nearly all of the rocks of the Ozark uplift is Cambrian, and the name "Ozark series," originally proposed by Broadhead, is adopted for them. Sandstones alternate with limestones, and these have been known as the first or saccharoidal, second and third sandstones, and the first, second, third, and fourth magnesian limestones. The saccharoidal sandstone has been generally correlated with the Calciferous of New York, and the St. Peter's of Minnesota and Wisconsin; and the magnesian limestones with the Lower Magnesian of the upper Mississippi Valley. Mr. Mason does not believe the evidence sufincient to make more than one sandstone and one limestone formation. For the first he proposes the name of Roubidoux sandstone, and for the second the name of Gasconade limestone. The outcrops of both sandstone and limestone have been correlated by lithological characters, but it is shown that the two rocks vary greatly. Sections taken along Current River for a distance of sixty miles and along the Gasconade for forty-eight miles show so much variation that it is impossible to trace the different sandstones or limestones with any certainty. There is, however, a stratum which bears fossils of the same general character over wide areas, and by its aid the connection between the sandstone and limestone can be traced. From the lists given it would appear that the affinities are more nearly with the Cambrian than the Lower Silurian epochs. The conclusions given will probably render a reconsideration of the age of certain beds at Eikie's quarry, near Baraboo, Wisconsin, necessary. These beds have been generally regarded as Lower Magnesian. They are probably more likely Potsdam. We have not space to go further into details, but we commend the volume to the consideration of geologists.

The second of our titles treats of a vastly different subject. The first part is taken up by a general discussion of mineral waters in respect to their origin, composition, etc.; and the second, by far the larger part, is devoted to a detailed account of the mineral 
springs of the State, with over 150 analyses of waters. The waters are divided into muriatic, alkaline, sulphatic, chalybeate, and sulphur. The origin of each of these is briefly discussed. The methods of analyses, classification, and therapeutic uses are also considered. For those who are especially interested in analyses of water and for the citizens of Missouri and other States who desire a knowledge of the location and uses of the various springs the volume is invaluable. It is a volume to be consulted rather than one to be read.

Washington, May 13, 1893. JOSEPH F. JAMES.

A Handy Book for Brewers. Being a Practical Guide to the Art of Brewing and Malting. By Herbert Edwards Wright, M.A. London, Crosby, Lockwood, \& Son. 530 p. $8^{\circ}$

Mr. WRIGHT has, in the present volume, expanded and enlarged an earlier work well known to the profession, entitled, "A Handbook for Young Brewers," giving the conclusions of modern research in so far as they bear upon the practice of brewing, as well as much practical detail, manipulative and structural. Few books of the size other than mere statistical records contain the amount of information herein included, and if the author has sacrificed styie to space it can not be considered a fault in this instance. The book is not intended for general reading, but for the student of brewing, and is to supplement rather than to supplant practical teaching at the works. There is much, however, that is of value to others, both to chemist and to general scientist, as witness the excellent chapters on water, the laboratory, on ferments and fermentation, yeasts, etc. The latter subjects in particular are cleverly treated, and nowhere do we remember seeing the various theories and hypotheses massed together so conveniently for comparison and ready reference. Complete details of malting and brewing operations are carefully given, differing customs are placed in juxtaposition, and in all cases the scientific discussion of chemical and vital changes accompanies the description of the process. It is unfortunate that the glossary originally planned as an appendix to the text was finally omitted, as there are few industrial operations with more technical and "shop" expressions than brewing, and the free use of these in some of the chapters - the author resting, of course, upon his intended glossary-would be rather confusing to the uninitiated. The subject is one of many ramifications, and as such could more easily be handled in three volumes than in one, but Mr. Wright has succeeded admirably with this difficult condensation, and has omitted nothing essential to a thorough knowledge of the subject.

C. P.

An Outline of the Documentary History of the Zuñi Tribe. BY A. F. BANDelier. Somatological Observations on Indians of the Southwest. BY DR. Herman F.C. TEN KATE. In a Journal of American Ethnology and Archoeology. J. Walk; Ferwkes, editor. Vol. III. Boston and New York, Houghton, Mifflin, \& Co. 1892.

THE scientific work accomplished by the Hemenway Expedition is gradually becoming known to the world through the medium of Dr. Fewkes's journal. The documentary history of the Zuñis during the 16th and 17th centuries, by Mr. Bandelier, is of absorbing interest and reflects the vast labor that had been expended in its compilation. In the identification of the Seven Cities of Cibola with the ancient Zuñi pueblos, the evidence formerly adduced is made so conclusive, by the introduction of new data, that it seems impossible for any one to fail to be convinced. The events which led to the Pueblo uprising against the Spaniards in 1680 are minutely recorded. Probably half the paper is devoted to copious notes and citations from original sources - principally manuscripts now in the hands of the Expedition. On page 114, the date of Fray Juan del Bal's arrival in New Mexico is given as 1771 , instead of 1671 , an obvious misprint, as the missionary was killed in the revolt above alluded to.

The second part of the volume is a summary report by Dr. ten Kate of his anthropologic observations of the Pima, Papago, Maricopa, Yuma and Zuñi Indians, as well as of the human remains found in the ruined puebles of the Salado Valley, Arizona, and in one of the Cibolan cities. Although the investigations of Dr. ten Kate and Mr. Cushing were from totally different points of view they unite in the conclusion that " the pre-Columbian Arizonians were closely related to the Zuñis of to-day." In the opinion of Dr. ten Kate the types of North American Indians are not exclusively American, but present only the characteristics of the Mon.
Reading Matter Notices.

Ripans Tabules : best liver tonic. Ripans Tabules cure jaundice.

ACK NUMBERS and complete sets of leading Mag azines. Rates low. AM. MAG. EXCHANGE
Schoharie, N. Y.

\section{RESTORE YOUR EYESIGHT}

Cataracts, scars or films can be absorbed and paralyzed nerves restored, without tho knife our home treatment. "We prove it." Hun dreds convinced. Our Mllustrated pamphlet, "Home Treatment for Eyes," free. Don't miss it.

BUSINESS OPPORTUNITY.

There is an opening for a young man to open a New York office of the American Lightning Protection Co., operating under my patents. But little capital will be required.

\section{N. D. C. HODGES,} 874 BROADWAY, NEW YORK! Removed to 64 East 12th Street, New York
TTHE MODERN MALADY; or, SUf- $\mid$ |ne ferers from 'Nerves.'

An introduction to public consideration, from a non-medical point of view, of a condition of ill-health which is increasingly prevalent in all ranks of society. In the first part of this work the author dwells on the errors in our mode of treating Neurasthenia, consequent on the wide ignorance of the subject which still prevails; in the second part, attention is drawn to the principal causes of the malady. The allegory forming the Introduction to Part I. gives a brief history of nervous exhaustion and the modes of treatment which have at various times been thought suitable to this most painful and trying disease.

\section{By CYRIL BENNETT.} $12^{\circ}, 184$ pp., $\$ 1.50$.

N. D. C. HODGES, 874 Broadway, N. Y. Minerals, Gems, Microscopical Sections, Fine Lapidary Work.

GEO. L. EKGLLSH \& CO., Mineralogists, MINERALS Now store.

New Departments.
Pennsylvania Bedford Springs Mineral Water For Liver, Kidney and Bladder Troubles. For Gravel, Gall Stones, Jaundice. For Dyspepsia, Rheumatism and Gout. For Hemorrhoids, Etc.

It has been used medicinally and prescribed by physicians for nearly one hundred years. DIRECTIONS:-Take one or two glasses about a alf-hour before each meal.

Case One Dozen Half-Gallon Bottles, $\$ 4.50$

Q

Bedford Mineral Springs Co., Bedford, $\mathrm{Pa}$. Philadelphia Office, 1004 Walnut St.
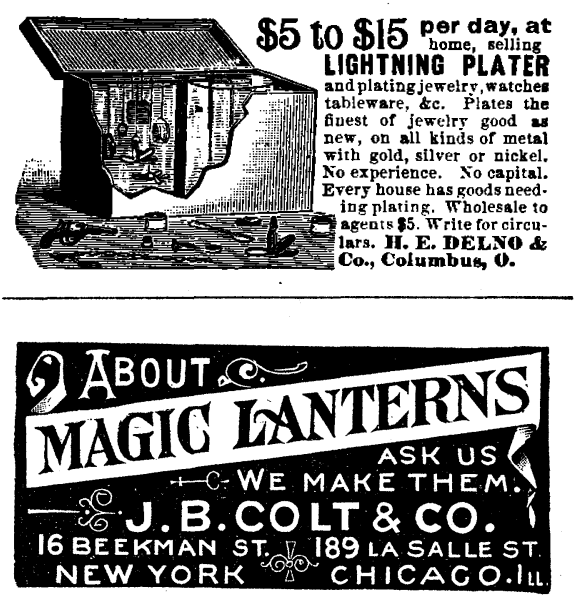

Kindly mention "Science" in writing to Advertisers. 